\title{
PELATIHAN PENGOLAHAN MINYAK JELANTAH MENJADI LILIN AROMA DAUN JERUK UNTUK IBU-IBU PKK KELURAHAN SUNGAI PINANG LUAR SAMARINDA
}

\author{
Rusdi1), Deny Kurniawan'1) \\ 1)Program Studi DIII Kesehatan Lingkungan, Fakultas Kesehatan Masyarakat, \\ Universitas Muhammadiyah Kalimantan Timur, Samarinda, Kalimantan Timur, Indonesia \\ Corresponding author : Rusdi \\ E-mail : rus756@umkt.ac.id
}

Diterima 10 Juni 2021, Direvisi 23 Juni 2021, Disetujui 24 Juni 2021

\begin{abstract}
ABSTRAK
Permasalahan utama yang dihadapi oleh pihak kelurahan Sungai Pinang Luar Samarinda adalah penggunaan minyak jelantah yang berulang kali oleh ibu rumah tangga untuk menggoreng makanan dan membuang minyak jelantah tersebut sembarangan. Pengabdiaan ini bertujuan untuk memberikan pemahaman kepada ibu-ibu PKK kelurahan Sungai Pinang Luar Samarinda tentang bahayanya penggunaan minyak jelantah yang digunakan berulangkali bagi kesehatan dan pembuangan minyak jelantah ke lingkungan yang akan mengganggu stabilitas ekologi pada lingkungan tersebut, sehingga dibentuk sebuah upaya tindakan melalui pelatihan pengolahan minyak jelantah menjadi sesuatu yang bernilai ekologis dan ekonomis. Metode yang digunakan dalam pengabdian ini adalah pelatihan langsung kepada ibu-ibu PKK di kelurahan Sungai Pinang Luar dalam pembuatan lilin aroma daun jeruk dari minyak jelantah. Hasil pengabdian ini terlihat antusiasme peserta untuk mencoba membuat sendiri lilin aroma daun jeruk dari minyak jelantah yang digunakan.
\end{abstract}

Kata Kunci: pelatihan; minyak jelantah; lilin aroma daun jeruk.

\begin{abstract}
The main problem faced by the Sungai Pinang Luar village Samarinda is the repeated use of used cooking oil by housewives to fry food and throw the oil carelessly. This service aims to provide an understanding to PKK women in Sungai Pinang Village, Luar Samarinda about the dangers of using used cooking oil repeatedly for health and the disposal of used cooking oil into the environment which will disrupt the ecological stability of the environment, so that an action effort is formed through oil processing training, waste cooking becomes something of ecological and economic value. The method used in this service is direct training to PKK women in Sungai Pinang Luar village in making orange leaf scented candles from used cooking oil. The results of this service were seen by the enthusiasm of the participants to try to make their own orange leaf scented candles from the used cooking oil.
\end{abstract}

Keywords: training; cooking oil; citrus leaf scented candle.

\section{PENDAHULUAN}

Aktivitas kegiatan di dapur seperti memasak dapat menghasilkan limbah, salah satu contoh adalah minyak jelantah. Tahun 2019 konsumsi minyak goreng Indonesia menghasilkan minyak jelantah sebanyak 16,2 juta kilo liter dan hanya $18,5 \%$ sisa konsumsi minyak goreng dapat dikumpulkan sebagai bahan baku minyak jelantah (Sayni, 2021). Minyak jelantah mempunyai potensi yang besar dalam membahayakan kesehatan tubuh. Jelantah mengandung berbagai radikal bebas, yang setiap saat siap untuk mengoksidasi organ tubuh secara perlahan. Minyak jelantah apabila digunakan terus menerus secara berulang akan memberikan dampak bagi kesehatan dan berdasarkan hasil penelitian sebagai pemicu penyakit kanker dan jantung
(Hanum, 2016). Hal ini dapat disebabkan oleh pengelolaan limbah minyak goreng yang tidak sesuai dengan proses pengolahan yang benar sehingga dapat menimbulkan dampak bagi kesehatan dan lingkungan sekitar.

Walaupun jelantah yang diperoleh telah melalui penyaringan beberapa kali, namun proses ini tidak menghilangkan zat yang timbul setelah minyak goreng dipanaskan dengan suhu tinggi berulang kali. Pemakaian minyak yang berulang, akan timbul asam lemak trans. Selanjutnya, zat ini akan mempengaruhi metabolisme profil lipid darah yakni HDL kolesterol, LDL kolesterol dan total kolesterol yang kemudian menimbulkan penyumbatan pada pembuluh darah atau disebut atherosklerosis yang dapat memicu terjadinya 
hipertensi, stroke dan penyakit jantung koroner (Novitriani, 2013).

Permasalahan yang diperoleh berdasarkan hasil wawancara dengan pihak Kelurahan Sungai Pinang Luar Samarinda adalah bahwa terdapat ibu rumah tangga yang masih menggunakan minyak goreng bekas/jelantah berkali-kali untuk menggoreng makanan, dan tidak sedikit pula yang membuangnya ke lingkungan. Kondisi tersebut sangat memperhatinkan mengingat limbah minyak yang dibuat dapat mencemari air dan tanah disekitar lingkungan warga. Untuk menanggulangi hal tersebut, dilakukan berbagai upaya supaya limbah jelantah tidak menjadi masalah bagi lingkungan salah satunya dengan pemanfaatan kembali minyak jelantah yang tidak digunakan menjadi suatu bahan yang bermanfaat sehingga dapat mengurangi tingkat pencemaran lingkungan (Nane dkk, 2017). Kegiatan pemanfaatan kembali minyak jelantah dilakukan di Desa Kemiri, Tanjung Sari, Gunung Kidul dengan mengubah minyak jelantah menjadi sabun (Erviana, 2019). pengabdiaan yang dilakukan oleh Sundoro dkk (2020) untuk dalam memanfaatkan minyak jelantah sebagai lilin warna-warni juga dilakukan warga RT. 01 di Dusun Jetak Bolon Colomadu Karanganyar, sebagai wujud pemberdayaan masyarakat, diperoleh hasil peningkatan pengetahuan warga mengenai dampak dari penggunaan minyak goreng jelantah dan bertambahnya pengetahuan peserta untuk mengolah minyak jelantah menjadi produk ramah lingkungan berupa lilin warna-warni.

Berdasarkan permasalahan tersebut maka tujuan dari kegiatan pengabdian pelatihan pengolahan minyak jelantah menjadi lilin aroma daun jeruk adalah (1) memberikan edukasi kepada ibu PKK kelurahan Sungai Pinang Luar Samarinda tentang efek yang ditimbulkan minyak jelantah baik ketika digunakan kembali maupun ketika dibuang ke lingkungan, (2) memberikan pelatihan pembuatan lilin dari minyak jelantah agar dapat menjadi suatu barang yang berguna dan memiliki nilai ekonomis.

\section{METODE}

Metode pelaksanaan pengabdian pengolahan minyak jelantah menjadi lilin aroma daun jeruk dilakukan dengan cara pelatihan atau workshop. Mitra dari kegiatan pengabdian ini adalah ibu-ibu PKK kelurahan Sungai Pinang Luar Samarinda. Adapun tahapan kegiatan pelatihan pengolahan minyak jelantah menjadi lilin aroma daun jeruk antara lain:
1. Tahap Identifikasi Permasalahan. Kegiatan ini dilakukan dengan wawancara kepada Lurah Sungai Pinang Luar terkait permohonan ijin untuk memfasilitasi proses pengabdian masyarakat, penentuan peserta serta waktu dan tempat pelaksanaan pelatihan.

2. Tahap Pelatihan. Pelaksanaan pelatihan dilaksanakan pada hari Sabtu, 5 Juni 2021 di posko Danau City RT. 26 kelurahan Sungai Pinang Luar, Samarinda. Kegiatan diawali oleh sambutan dari Lurah Sungai Pinang Luar, Samarinda dilanjutkan dengan pemberian materi dan pelatihan langsung kepada ibu-ibu PKK di RT. 26 Kelurahan Sungai pinang luar yang berjumlah 18 orang. Kegiatan ini dilaksanakan secara tatap muka dengan tetap mengikuti protokol kesehatan yaitu menggunakan masker dan menjaga jarak.

3. Tahap Evaluasi. Kegiatan ini bertujuan untuk mengevaluasi seluruh kegiatan sehingga dapat diketahui hasil yang diperoleh selama kegiatan berlangsung, permasalahan/kendala yang muncul, serta solusi pemecahannya dalam bentuk laporan akhir kegiatan pengabdian.

\section{HASIL DAN PEMBAHASAN}

\section{Tahap Identifikasi}

Hasil dari identifikasi permasalahan yang didapatkan dari hasil wawancara dengan pihak kelurahan Sungai Pinang Luar adalah ibu-ibu yang menggunakan minyak goreng dalam bentuk minyak jelantah yang dipakai berulang-ulang untuk mengoreng makanan serta pembuangan minyak jelantah yang sembarangan di sekitar lingkungan warga sehingga mencemari saluran/got. Hasil dari wawancara tersebut, kemudian tim PKM diarahkan oleh Lurah Sungai Pinang Luar dan berkoordinasi dengan ketua RT. 26 maka dilakukan kegiatan pengabdian masyarakat ini berupa pelatihan penolahan minyak jelantah menjadi lilin dengan aroma daun jeruk dengan melibatkan ibu-ibu PKK sebagai mitra.

\section{Tahap Pelatihan}

Pelatihan pengolahan minyak jelantah menjadi lilin aroma daun jeruk dilaksanakan pada hari Sabtu, 5 Juni 2021 pada pukul 08.30 - 12.00 WITA yang diadakan di posko relawan Danau City RT. 26, Jalan Danau Melintang, Kelurahan Sungai Pinang Luar, Samarinda. Kegiatan berlangsung dengan tatap muka ini diikuti 18 orang ibu PKK dengan tetap mengikuti protokol kesehatan yaitu memakai masker dan menjaga jarak. Pelatihan yang diberikan memberikan wawasan dan keterampilan baru bagi ibu-ibu PKK di lingkungan RT. 26 
mengenai pengolahan minyak jelantah menjadi lilin dengan memanfaatkan potensi lokal yaitu daun jeruk sebagai aroma.

Kegiatan pelatihan ini dilakukan dengan metode penyampaian materi berupa definisi minyak jelantah, efek/bahaya minyak jelantah bagi tubuh jika terus dikonsumsi secara berulang seperti dapat terjadinya infeksi bakteri, meningkatkan risiko kanker, meningkatkan risiko penyakit degeneratif seperti penyakit jantung, dan memicu terjadinya kelebihan berat badan atau obesitas serta membuang minyak jelantah ke lingkungan dapat mencemari tanah dan sumber air, karena sifatnya yang sulit menyatu dan sulit terurai atau dengan kata lain terganggunya stabilitas ekologi pada lingkungan tersebut. Salah satu solusi yang dapat ditempuh dalam penggunaan jelantah yang aman dengan pengolahannya menjadi lilin beraroma daun jeruk (Gambar 1).

Lilin dapat menjadi alternatif sumber cahaya/penerangan dan daun jeruk memiliki salah satu khasiat sebagai aromaterapi. Tim PKM juga memberikan pemaparan tentang alat-alat dan bahan-bahan yang digunakan dalam proses pembuatan lilin beraroma daun jeruk dari minyak jelantah yakni kompor, panci, gelas ukur, timbangan digital, sendok, cetakan silikon, benang katun, stearin, serbuk daun jeruk serta minyak jelantah.

Daun jeruk yang telah diproses menjadi bubuk dijadikan bahan campuran dalam pembuatan lilin karena aroma daun jeruk dapat menjadi aromaterapi sehingga dapat memberikan aroma lilin yang segar dan wangi serta aroma dari minyak jelantah yang pada dasarnya berbau tengik dapat dinetralisir dengan campuran daun jeruk tersebut.

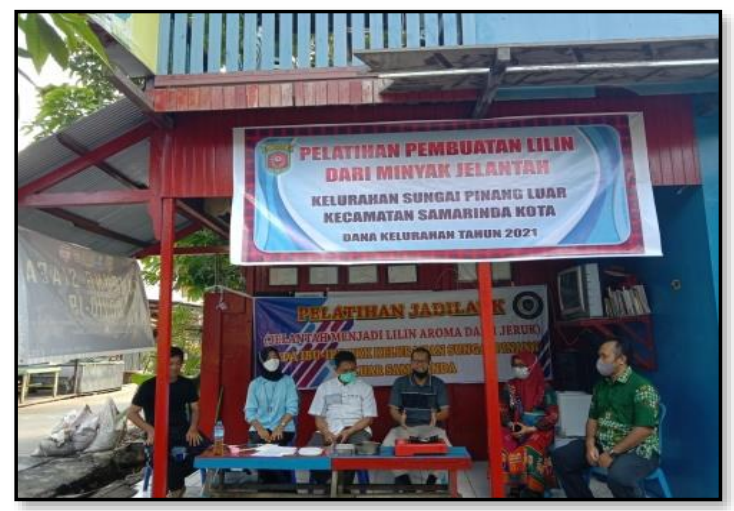

Gambar 1. Penyampaian materi dari Tim PKM

Pada pelatihan ini, partisipasi aktif dari ibu-ibu PKK untuk mempraktekkan langsung pembuatan lilin dari minyak jelantah merupakan indikator keberhasilan PKM. Dalam pembuatan lilin, minyak jelantah yang digunakan terlebih dahulu dimurnikan menggunakan karbon aktif agar mendapatkan warna yang sesuai.

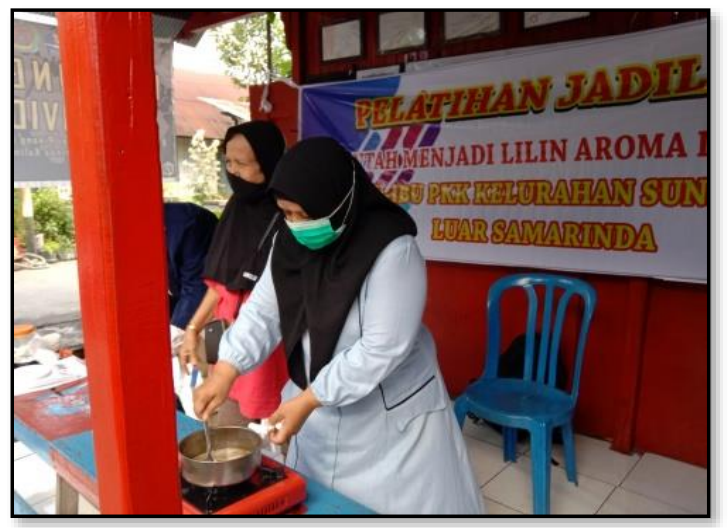

Gambar 2. Partisipasi ibu PKK untuk mempraktekkan pembuatan lilin aroma daun jeruk dari minyak jelantah

Gambar 2 merupakan proses praktek pembuatan lilin dari ibu PKK yang didampingi oleh dosen dan mahasiswa DIII Kesehatan Lingkungan Universitas Muhammadiyah Kalimantan Timur. Kegiatan ini sebagai kolaborasi dosen dan mahasiswa dalam mengaplikasikan ilmu yang diperoleh kepada masyarakat luas.

Prosedur pembuatan lilin aroma daun jeruk dari minyak jelantah yang dilakukan oleh tim PKM adalah sebagai berikut:

a. Diukur minyak jelantah sebanyak $50 \mathrm{ml}$ dengan menggunakan gelas ukur;

b. Ditimbang stearin sebanyak $100 \mathrm{gr}$ dengan menggunakan timbangan digital;

c. Dimasukkan minyak jelantah yang telah ditimbang tadi kedalam panci kemudian panaskan panci yang berisi minyak jelantah tersebut di atas kompor;

d. Setelah minyak jelantah cukup panas selanjutnya dicampurkan stearin dan daun jeruk secukupnya ke dalam panci tersebut,hingga homogen;

e. Setelah homogen selanjutnya larutan lilin dituangkan ke cetakan silokon dan diberi benang katun di bagian tengah cetakan tersebut. Larutan lilin yang telah dibuat harus dituangkan ke cetakan silokon agar bentuk lilin menjadi lebih beraturan dan terlihat lebih estetis (Gambar 3). 


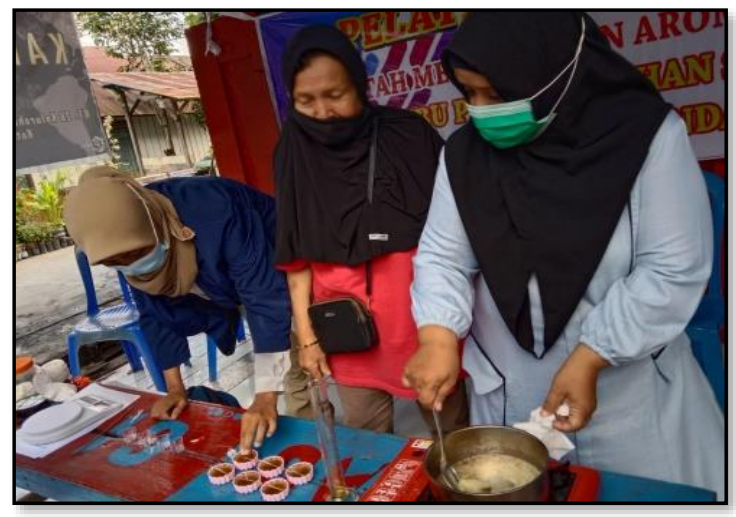

Gambar 3. Pencetakan lilin pada cetakan

f. Tahap selanjutnya dari kegiatan PKM ini adalah membiarkan terjadinya pengerasan lilin pada cetakan silikon. Pengerasan lilin membutuhkan waktu kurang lebih 1 jam. Setelah kurang lebih 1 jam, maka lilin telah terbentuk secara padat dan telah dapat dikeluarkan dari cetakan silikon tersebut (Gambar 4).

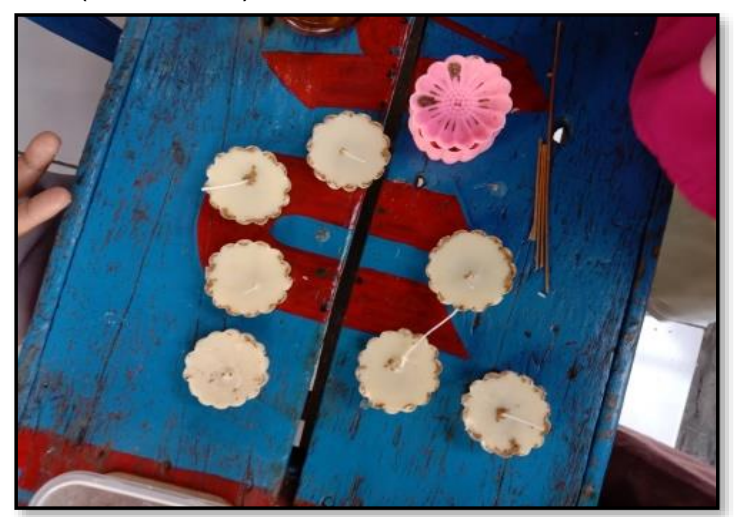

Gambar 4. Lilin telah terbentuk

Tahap terakhir dari kegiatan ini yakni melakukan evaluasi terhadap keberhasilan pembuatan lilin aroma daun jeruk dari minyak jelantah. Untuk mengetahui keberhasilan dalam pembuatan lilin dilakukan dengan menyalakan api pada sumbu lilin dan didapatkan hasil berupa api menyala pada sumbu lilin tersebut (Gambar 5).

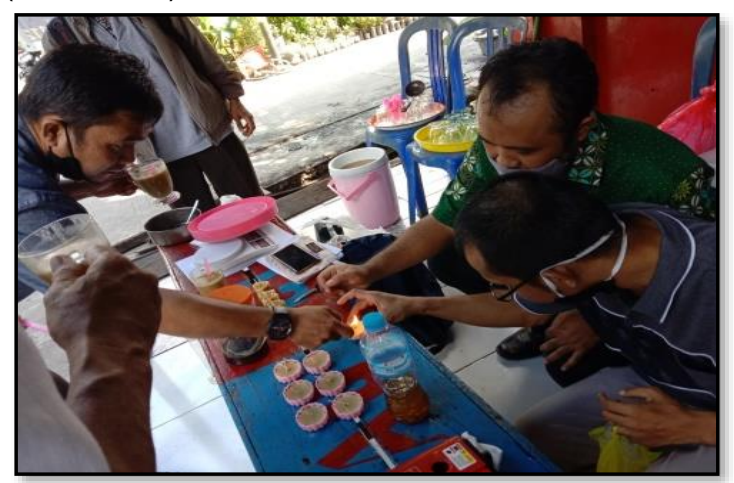

Gambar 5. Menyalakan lilin

\section{Tahap Evaluasi}

Pada tahap terakhir dari kegiatan pelatihan ini adalah evaluasi kegiatan dan rencana tindak lanjut. Respon positif dan antusias dari ibu PKK RT. 026 Kelurahan Sungai Pinang Luar adalah cukup baik, pelaksanaan pelatihan dan transformasi pengetahuan dari tim PKM berjalan lancar. Tindak lanjut yang dilakukan tim PKM adalah melakukan wawancara non formil untuk mendapatkan informasi dari mitra pengabdian tentang pengetahuan pemanfaatan limbah minyak jelantah yang telah disosialisasikan.

\section{SIMPULAN DAN SARAN Simpulan}

Kegiatan pengabdian dalam pembuatan lilin aroma daun jeruk dari minyak jelantah berjalan dengan baik serta para peserta sangat bersemangat untuk mencoba mempraktekan secara mandiri dalam pembuatan lilin aroma daun jeruk dari minyak jelantah. Selain itu peserta semakin memahami efek negatif minyak jelantah jika digunakan kembali untuk menggoreng bahan makanan, serta dapat memberi efek buruk pada lingkungan jika dibuang sembarangan.

\section{Saran}

Perlu dilakukan selalu pendampingan dan evaluasi terhadap para ibu-ibu di lingkungan Kelurahan Sungai Pinang Luar Samarinda dengan dukungan Lurah beserta jajarannya dalam penerapan pengolahan minyak jelantah menjadi lilin aroma daun jeruk. Selain itu perlu dilakukan pula pembuatan lilin dari minyak jelantah dengan aroma yang bervariasi.

\section{UCAPAN TERIMAKASIH}

Terimakasih kami haturkan kepada Bapak Lurah Sungai Pinang Luar Samarinda yakni Bapak Drs. Abdullah, M.Pd dan ibu-ibu PKK RT. 26 Kelurahan Sungai Pinang Luar Samarinda yang telah membantu menyukseskan kegiatan PKM ini, serta tentunya juga kami tidak lupa sampaikan pula ucapan terimakasih kepada Rektor Universitas Muhammadiyah Kalimantan Timur dan LPPM Universitas Kalimantan Timur yang telah mensupport dalam pendanaan atas PKM ini.

\section{DAFTAR RUJUKAN}

Angga. 2012. Pengaruh Pemberian Arang Aktif Terhadap Minyak Jelantah. Universitas Semarang: Semarang.

Erviana, Vera Y. 2019. Pelatihan Pengolahan Minyak Jelantah menjadi Sabun dan Strategi Pemasaran di Desa Kemiri. Jurnal Pemberdayaan: Publikasi Hasil 
Pengabdian kepada Masyarakat. Vol 3. No. 1. Hal. 17-22 ISSN:2580-2569;eISSN: 2656-0542

Hanum, Y. 2016. Dampak Bahaya Makanan Gorengan bagi Jantung. Keluarga Sehat Sejahtera, 14(28), 103-114.

Kahar. 2004. Respon Minyak Jelantah Terhadap Pemberian Sekam Padi. Universitas Semarang: Semarang.

Koensoemardiyah. 2009. Aromaterapi Untuk Kesehatan Kebugaran dan Kecantikan. Edisi I. Lily Publisher: Yogyakarta.

Nane, E., Imanuel, G. S., \& Wardani, M. K. 2017. Pemanfaatan Jelantah Sebagai Bahan Alternatif Pembuatan Lilin.

Novitriani, K. 2013. Pemurnian Minyak Goreng Bekas. Jurnal Kesehatan Bakti Tunas Husada 9 no. 1 (2013).

Prabandari, S. 2017. Formulasi dan Aktivitas Kombinasi Minyak Jeruk dan Minyak Sereh Pada Sediaan Lilin Aromaterapi. Jurnal Para Pemikir 6 no.1 (2017).

Raharja, S., Setyaningsih, D., Turnip. 2006. Pengaruh Perbedaan Komposisi Bahan, Konsetrasi dan Jenis Minyak Atsiri Pada Pembuatan Lilin Aromaterapi. Jurnal Teknologi Pertanian 1 no. 2 (2006).

Sidjabad. 2004. Kandungan Minyak goreng. Erlangga: Jakarta.

Sundoro, T., Erna Kusuma, Fatma Auwalani. 2020. Pemanfaatan Minyak Jelantah Dalam Pembuatan Lilin Warna Warni. Jurnal Pengabdian Masyarakat Ipteks. Vol. 6 No. 2 Desember Hal. 127-136 eISSN: 2528-116X; p-ISSN: 2527-5216

Syahni, Della. 2021. Ini keuntungan kalau minyak jelantah jadi biodiesel. Mongabay; Situs Berita Lingkungan. https://www.mongabay.co.id/2021/01/0 3/ini-keuntungan-kalau-minyakjelantah-jadi-biodiesel/.

Diakses tanggal 21 Juni 2021.

Winarno. 2004. Minyak Goreng Dalam Menu Masyarakat. Balai Pustaka: Jakarta.

Yustinah. 2004. Adsorbsi Minyak Goreng Bekas Menggunakan Arang Aktif dari Sabut Kelapa. Prosiding, seminar Nasional Teknik Kimia, Yogyakarta. 